\title{
Explanation of the Perceptions of Women with Prediabetes Affecting Physical Activity: A Qualitative Study
}

\author{
Research Article
}

\begin{abstract}
Seyed Saeed Mazloomy Mahmoodabad ${ }^{1}$, Fereshteh Sohrabi Vafa ${ }^{2 *}$, Ali Akbar Vaezi ${ }^{3}$, Hamid karimi ${ }^{4}$, Hosein Fallahzadeh ${ }^{5}$

1. Social Determinants of Health Research Center, Department of health education and promption, School of Public Health, Shahid Sadoughi University of Medical Sciences, Yazd, Iran.

2. Social Determinants of Health Research Center, Department of Health Education and Promotion, School of

Public Health, Shahid Sadoughi University of Medical Sciences, Yazd, Iran.

3. Department of Nursing, School of Nursing \& Midwifery, Research Center for Nursing \& Midwifery Care in

Family Health, Shahid Sadughi University of Medical Science, Yazd, Iran.

4. Department of Medicine, Dezful University of Medical Sciences, Dezful, Iran.

5. Department of Biostatistics, Research Center of Prevention \& Epidemiology of Non-Communicable Disease, Shahid Sadoughi University of Medical Sciences, Yazd, Iran.
\end{abstract}

\begin{abstract}
Background and aim: a healthy and active lifestyle is an essential determinant of any individual's health. And the individual's perceptions of the diseases will impact the way preventive behaviors are adopted, the way the individual adapts to the disease, disease management and, overall, the prevention of disease progress. The aim of the present study was explaining women's perception of regular physical activity based on PEN-3 model. Material and Method: this study is qualitative and of directed content analysis type. 41 women with prediabetes and 9 employees of health centers, using purposeful sampling, were entered into this study. The data were obtained using individual semi-structured interviews based on PEN-3 model. Graneheim and Lundman's method was used for data analysis. Result: during the data analysis process, a main category that included perceptional factors regarding physical activity and 6 sub-categories including knowledge, attitude, perceived benefits, perceived threat, perceived barriers and Self-efficacy were extracted from the data text. Conclusion: The findings obtained were positive and negative perceptions of women with prediabetes regarding physical activity in a sociocultural scope that can be considered in designing interventions based on PEN-3 model for changing and improving exercise behavior in women with prediabetes.
\end{abstract}

Keywords: Women, Prediabetes, Perceptions, PEN-3 model, Physical Activity.

\section{Introduction}

Prediabetes is a condition that is considered as one of the initial stages of diabetes. In this condition, the individual's blood glucose is between normal state and diabetic state and it is a significant risk factor for progress to type 2 diabetes and it alone can also increase the risk of problems such as cardiovascular damage. Compared with healthy individuals, individuals with prediabetes are 20 times more likely to be afflicted with diabetes $(1,2)$. It is estimated that the prevalence of diabetes in the world will surpass 438 million individuals by the year 2030 (3). Studies indicate that in at-risk individuals, especially those with prediabetes, the change in lifestyle such as weight loss,

*Corresponding Author:

Fereshteh Sohrabi Vafa,

Social Determinants of Health Research Center,

Department of Health Education and Promotion,

School of Public Health, Shahid Sadoughi University of Medical Sciences, Yazd, Iran.

Email id: drfreshtehsohrabivafa@gmail.com physical activity and exercise, accompanied by an appropriate diet, is a very effective method for prevention or at least delaying of type 2 diabetes. Therefore, having essential information of at-risk individuals' knowledge and attitudes for advancement of preventive programs is necessary $(4,5)$. Regular physical activity, in addition to controlling diabetes, has other benefits such as helping weight loss, maintaining normal weight, prevention of cardiovascular diseases, reduction of blood lipid and reduction of blood pressure as well as positive psychological effects such as reduction of stress and anxiety $(6,7)$. According to the existing statistics, the number of diabetic women is higher than men due to less physical activity in women and, in some studies, it has been suggested to study these patients separately by sex (8). Despite the confirmed effect of physical activity on diabetes and prediabetes, the afflicted individuals do not adopt these behaviors and this results in the progress of the disease and emergence of complications in them. Therefore, it is necessary to identity and explain the factors impacting the behaviors in question based on an appropriate mode, 
before any intervention. One of the models for studying behavior in the domain of health education and promotion is PEN-3 model that explores factors impacting the individual's behaviors by paying attention to the culture explored (9). This model begins by identifying the individuals' beliefs and experiences regarding the problem in question, using a qualitative research, and finally, an appropriate educational program based on the results obtained from the qualitative study is designed $(10,11)$. Positive and negative perceptual factors include knowledge, belief, attitudes and values that, as facilitators or inhibitors, have a significant role in doing physical activity behavior. The identification of these factors can be a solution in preventing the affliction with type 2 diabetes among women. Therefore, the objective of this study was explaining the perceptions of women with prediabetes regarding regular physical activity and exercise using PEN-3 cultural model.

\section{Material and Methods}

Directed content analysis approach based on PEN-3 model was used in the present qualitative method. 41 individuals with prediabetes and 9 health care providers participated in this study. The participators were selected during February 2017 to November 2017, using purposeful sampling, from four urban and rural health centers in the county of Dezful. The data were collected using face to face and semi-structured individual in-depth interviews based on PEN-3 model. The interview duration was 30-45 minutes and the number of interviews varied from 1 to 3 . At the beginning of each interview, the aim of the study was explained to the participants and informed consent was obtained from them. Afterwards, the interviews were recorded. The interview guiding question was "explain one day of your life in which you have physical activity" and the expressed aspects were deeply explored using appropriate probing questions such a "give an example for this" and "please elaborate on that" and by considering the PEN-3 model constructs (factors of perceptual, enabling, reinforcing). The interviews were continued until data saturation in a way that no new codes were obtained in the subsequent interviews. The data were analyzed using Graneheim and Lundman's method. For this purpose, after each interview session, the recorded data were listened to by the researcher at the first opportunity. Then the text was read several times to obtain an in-depth and correct understanding of it and the texts were given an appropriate code. Then the similar codes or the codes with similar meaning and understanding were placed in the same group (12). On this basis, in this study an initial categorization of the data was obtained that included secondary subcategories, subcategories and categories. In order to achieve the accuracy and validity of the study, the criteria presented by Lincoln and Guba i.e. credibility, dependability (reliability) confirmability, and transferability were considered and employed (13). In the present study, in order to fulfill data credibility, review methods by colleague and review by the participants was used. In order to verify the process of conducting the work and accuracy of the implementation of the study i.e. conformability of the data, the data were controlled by some colleagues in the study (supervisor and advisor). In order to fulfill the dependability of the data, the exact expressions of the participants in the form of quotations were recorded in the qualitative results section of the study. In order to assess the transferability of the data, the method of maximum diversity in the participants was employed and the accuracy and validity of the study was ensured. This study is a part of the results of a thesis approved by Shahid Sadoughi University of Medical Sciences and Health Services, and, before the start of the study, the approval of the authorities of the related centers was obtained.

\section{Result}

The individual and social particulars of the women with prediabetes in this study are according to the following table.

Table 1: Social-individual particulars

\begin{tabular}{|l|l|}
\hline Age mean (years) & 45 \\
\hline $\begin{array}{l}\text { Body mass index (BMI) mean } \\
\text { (Kg/m } \mathbf{m}^{2}\end{array}$ & 27.8 \\
\hline $\begin{array}{l}\text { The education of the majority } \\
\text { (under diploma) }\end{array}$ & $58.5 \%$ \\
\hline $\begin{array}{l}\text { The marital status of the majority } \\
\text { (married) }\end{array}$ & $73.17 \%$ \\
\hline $\begin{array}{l}\text { The employment status of the } \\
\text { majority (housewives) }\end{array}$ & $63.4 \%$ \\
\hline $\begin{array}{l}\text { The number of participants with } \\
\text { prediabetes }\end{array}$ & $\begin{array}{l}41 \\
\text { individuals }\end{array}$ \\
\hline
\end{tabular}

Table 2: The process of formation of initial codes resulted from semantic meanings

\begin{tabular}{|c|c|}
\hline Semantic units & Initial codes \\
\hline $\begin{array}{l}\text { "Exercise is very good. I think } \\
\text { that I am overweight and my } \\
\text { blood glucose is at the } \\
\text { borderline due to not walking at } \\
\text { all" }\end{array}$ & $\begin{array}{l}\text { Having knowledge of } \\
\text { obesity due to lack of } \\
\text { physical activity } \\
\text { Having knowledge of } \\
\text { borderline blood } \\
\text { glucose due to lack of } \\
\text { physical activity }\end{array}$ \\
\hline $\begin{array}{l}\text { "I showed my test result to my } \\
\text { doctor and she said that I should } \\
\text { walk but she did not say how or } \\
\text { when the appropriate time for } \\
\text { that is" }\end{array}$ & $\begin{array}{l}\text { Lack of knowledge of } \\
\text { the appropriate time } \\
\text { for walking during } \\
\text { the day }\end{array}$ \\
\hline $\begin{array}{l}\text { "I don't know to how much I } \\
\text { should walk in a week or, for } \\
\text { example, is half an hour of } \\
\text { walking enough or there is a } \\
\text { need for one hour to impact my } \\
\text { blood glucose" }\end{array}$ & $\begin{array}{l}\text { Lack of knowledge of } \\
\text { the appropriate } \\
\text { duration of walking } \\
\text { effective for blood } \\
\text { glucose control }\end{array}$ \\
\hline
\end{tabular}


Table 3: The process of formation of subcategorieses and categorieses

\begin{tabular}{|c|c|c|c|}
\hline Code & $\begin{array}{c}\text { Secondary } \\
\text { subcategories }\end{array}$ & subcategories & categories \\
\hline $\begin{array}{c}\text { Having knowledge of borderline blood glucose due to lack of } \\
\text { physical activity } \\
\text { Knowledge of the hereditariness of the disease }\end{array}$ & $\begin{array}{l}\text { Knowledge of the } \\
\text { cause of affliction } \\
(+)\end{array}$ & \multirow{4}{*}{ knowledge } & \multirow{14}{*}{$\begin{array}{l}\text { Perceptual } \\
\text { factors }\end{array}$} \\
\hline $\begin{array}{c}\text { Lack of knowledge of the appropriate time for walking } \\
\text { during the day } \\
\text { Lack of knowledge of the appropriate time for walking } \\
\text { considering eating time }\end{array}$ & \multirow{3}{*}{$\begin{array}{l}\text { Lack of } \\
\text { knowledge of the } \\
\text { way to do physical } \\
\text { activity (-) }\end{array}$} & & \\
\hline $\begin{array}{c}\text { Lack of knowledge of the adequate walking duration in a } \\
\text { week } \\
\begin{array}{c}\text { Lack of knowledge of adequate duration of swimming in a } \\
\text { week }\end{array}\end{array}$ & & & \\
\hline $\begin{array}{c}\text { Lack of knowledge of the appropriate exercise considering } \\
\text { having arthritis } \\
\text { Lack of knowledge of the appropriate exercise considering } \\
\text { having backache }\end{array}$ & & & \\
\hline $\begin{array}{l}\text { Enjoying swimming pool } \\
\text { Walking willingly }\end{array}$ & Enjoyableness $(+)$ & \multirow{6}{*}{ Attitudes } & \\
\hline $\begin{array}{l}\text { Interest in going to gym and more passion by seeing others } \\
\text { Interested in walking collectively with friends }\end{array}$ & $\begin{array}{l}\text { Preferring group } \\
\text { exercise }(+)\end{array}$ & & \\
\hline $\begin{array}{l}\text { Belief in lack of necessity of walking due to having a lot of } \\
\text { activities at home } \\
\text { Considering work and exercise to be similar }\end{array}$ & $\begin{array}{l}\text { Inappropriate } \\
\text { understanding(-) }\end{array}$ & & \\
\hline $\begin{array}{c}\text { Believing in tiresomeness of exercise and reduction of energy } \\
\text { after doing it } \\
\text { Being inclined to sleep after exercise due to tiredness }\end{array}$ & Tiresomeness(-) & & \\
\hline $\begin{array}{c}\text { Lack of belief in exercise due to inclination towards eating } \\
\text { more after doing it } \\
\text { Belief in gaining weight by exercising }\end{array}$ & $\begin{array}{l}\text { Overeating and } \\
\text { obesity as the } \\
\text { cause of lack of } \\
\text { physical activity(-) }\end{array}$ & & \\
\hline $\begin{array}{l}\text { Considering diet to be more important than physical activity } \\
\text { Belief in the lack of necessity of physical activity with the } \\
\text { reduction of carbohydrate intake }\end{array}$ & $\begin{array}{l}\text { Preferring diet to } \\
\text { physical activity(-) }\end{array}$ & & \\
\hline $\begin{array}{l}\text { Belief in the role of physical activity in controlling blood } \\
\text { glucose } \\
\text { Belief in the role of physical activity in losing weight }\end{array}$ & Physical health $(+)$ & \multirow[t]{4}{*}{$\begin{array}{l}\text { Perceiving the } \\
\text { benefits of } \\
\text { physical } \\
\text { activity }\end{array}$} & \\
\hline $\begin{array}{l}\text { Reduction of anxiety and stress by walking } \\
\text { Improvement of spirit and mood by exercising }\end{array}$ & Mental health $(+)$ & & \\
\hline $\begin{array}{l}\text { Belief in the role of physical activity in preventing physical } \\
\text { complications such as food ulcers } \\
\text { Belief in the role of physical activity in preventing diabetic } \\
\text { retinopathy }\end{array}$ & $\begin{array}{c}\text { Prevention of } \\
\text { complications }(+)\end{array}$ & & \\
\hline $\begin{array}{c}\text { Belief in the lack of need to consume medicine with walking } \\
\text { Doing regular physical activity for preventing the necessity } \\
\text { of consuming medicine }\end{array}$ & $\begin{array}{l}\text { Lack of need to } \\
\text { consume medicine } \\
\qquad(+)\end{array}$ & & \\
\hline
\end{tabular}




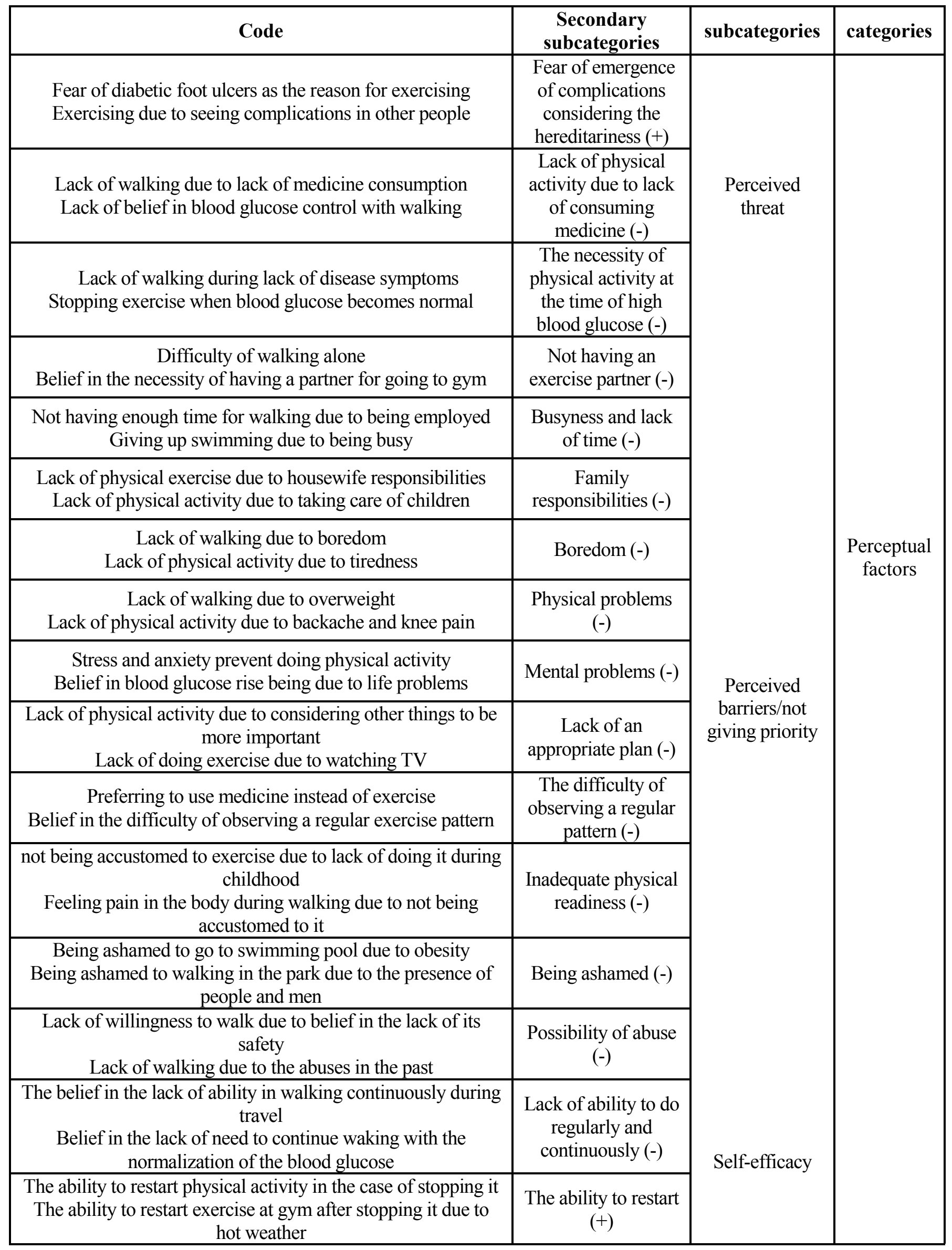

Positive Perceptions (+ - (Likely to promote or enhance behavior

Negative Perceptions (- - (Likely to have an adverse influence on health 
As mentioned in table 3, the concept of the categories "perceptual factors" is the result of six subcategorieses that are explained below.

\section{Perceptual factors}

Knowledge:

\section{Knowledge of the cause of affliction}

Some participants, in addition to having prediabetes, were afflicted to other diseases such as high blood lipids and obesity and pointed out the cause of their affliction to be lack of physical activity. Some other participants pointed out genetics, in addition to lack of activity, as a factor influencing the rise in their blood glucose.

"Exercise is very good. I think that both my obesity and borderline blood glucose are due to the fact that I do not walk at all. (Participant No. 2).

\section{Lack of knowledge of the way to do physical activity:}

One of the individual barriers pointed out by the participants was their lack of knowledge regarding the way of doing physical activity as they did not know the appropriate time for exercise, the necessary duration, the physical activity appropriate for their physical status and physical problem. For example, a participant in this regard said:

"I have knee pain and backache and the pain increases when I walk. I don't know what exercise I should to in order to not have a problem" (Participant No. 16).

\section{Attitude}

\section{Enjoyableness}

The participants pointed out physical activity to be enjoyable and they were interested in exercises such as walking and swimming. The participant No. 5 pointed out her experiences in this regard with sentences such as "I enjoy going to swimming pool and swimming and I feel good about it".

\section{Preferring group exercise to individual exercise}

The participants pointed out that when walking or swimming is done collectively or when there is an exercise partner, they have more passion and motivation and they enjoy the exercise more.

"I like group exercise more. When the number of individuals is high, I have more motivation" (Participant No. 9).

\section{Inappropriate understanding of physical activity}

The participants considered doing routine daily activities such as housework and occupational activities to be similar to and a substitute to physical activity.

"I have a lot of activities at home. With all these works I do from morning till night, I don't think there is a need for walking" (participant No. 14).

\section{Tiresomeness of physical activity}

Belief in the tiresomeness of physical activity was another reason for lack of doing physical activity by some participants. In this regard, the participant No. 17 said: "my sister always encourages me to go walking with her but it does not lead to anything but tiredness for me. Exercise is generally tiresome".

\section{Overeating and obesity as the cause of lack of physical activity}

Due to the increase of appetite and overeating after exercise, the participants preferred not to have physical activity. The participant No. 20 pointed out her experiences in this regard with sentences such as: "whenever I go walking, my appetite doubles afterwards when I get home and I overeat a lot; it is better for me not to exercise at all".

\section{Preferring diet to physical activity}

The participants considered the role of diet in controlling blood glucose and even blood lipids to be more important. The center's physician pointed out her experiences in this regard as follows: "I always recommend my patients to walk in addition to a diet but they still do not pay attention and they think that diet is enough for them".

\section{Perceiving the benefits of physical activity 1. Physical health}

According to the participants exercise and physical activity are the cause of physical health and they had understood the benefits of them such as blood glucose control, weight loss and reduction of body pain. The participant No. 10 expressed her experiences in this regard in the form of the following sentences: "it is one month since I found out that my blood glucose is at the borderline. I exercise and my weight which was high is decreasing. I realized that exercise is highly effective".

\section{Mental health}

The participants considered doing physical activity to be the cause of their mental health. The participant No. 9 mentioned her experiences in this regard in the form of the following sentences: "the days I go to the gym it seems that I am happier and more amiable and my spirit is very good".

\section{Prevention of disease complications}

Participants pointed out one of the long term benefit of regular physical activity to be prevention of disease progress and affliction with diabetes as well as the prevention of the complications of diabetes such as foot ulcers, blindness, etc. The participant No. 22, in this regard, said: "if I do exercise, at least it will not rise to the extent that I become afflicted with complications because whomever with diabetes I have seen, they have been blinded, become afflicted with foot ulcers or have lost their kidneys". 


\section{Lack of need to consume medicine}

Another long term advantage of exercise among the participants was the lack of need to consume medicine. The participant No. 18, mentioned her experience in this regard as follows: "I walk so that my blood glucose does not rise to make me diabetic in which case I would have to consume medicine to control the diabetes".

\section{Perceived threat}

\section{Fear of emergence of complications of diabetes} due to family history

The participants who were aware of the complications of diabetes, had seen these complication in their family and believed in the hereditariness of diabetes viewed themselves to be more at risk of diabetes and its complications. The participants who had no diabetic in their family and who had not seen and were not aware of high blood glucose complications experienced less fear and did exercise less. The center's expert, in this regard, said: "the patients who have family history of diabetes and who have seen diabetic individuals and their problems feel that they are more at risk of diabetes or its complications and exercise and pay attention more".

\section{Lack of physical activity due to lack of consuming medicine}

The participants mentioned the lack of prescribing medicine by physicians for individuals with prediabetes as one of reasons for their lack of willingness to do physical activity and did not considered the recommendation to adopt self-care and especially having physical activity and walking as necessary and important. In this regard, the participant No. 19 said: "now that my blood glucose is at the borderline I should consume medicine to lower my blood glucose. The doctor says that I should observe my diet and walk but I do not believe in these things".

\section{The necessity of physical activity at the time of high blood glucose}

The participants had started exercise and walking but they had abandoned exercise after a while because they had no disease symptoms or their blood glucose was controlled.

"When my blood glucose is high I know. I go walking because I become hungry and thirsty a lot. I drink water. But when I have no symptoms I do not go waking" (participant No. 23).

\section{Perceived barriers/not giving priority}

\section{Not having an exercise partner}

One of the barriers for doing physical activity and exercise in women has been pointed out to be the lack of a partner. The participant No. 41 mentioned her experiences as follows: "I am not used to walking alone. I would like to have someone accompany me".

\section{Busyness and lack of time}

Many of the participants considered busyness including having a lot of work at workplace and consequently shortage of time as perceived time barriers for their lack of physical activity. "I don't have time for walking or going to the gym because I am employed and I also work outside of the house" (participant No. $35)$.

\section{Family responsibilities}

This was another reason for the lack of physical activity in women. For example, in this regard, participant No. 24 said:

"I do not walk at all as my work at home is very much and I become tired for the housework. If I find a time, I will rest".

\section{Boredom}

Laziness, boredom and tiredness were among other obstacles of physical activity in women with prediabetes. The participant No. 29. Expressed her experiences in this regard as follows: "I do not have a motivation for exercise at all. I have motivation for anything except exercise".

\section{Physical problems}

This was one of the perceived individual barriers pointed out by the participants. Participant No. 32 mentioned her experiences in this regard as follows: "I like exercise a lot but, due to my backache and knee pain, I do not think that I can go walking”.

\section{Mental problems}

The participants considered their different routine stresses and problems and mental problems such as depression and anxiety as the cause of their high blood glucose and the cause of their inability in physical activity. The participant No. 38 expressed her experience as follows: "I go on walking but not regularly. I have depression which does not allow me to exercise regularly".

\section{Lack of an appropriate plan}

Participant No. 33 pointed out her experiences in this regard in the form of the following sentences: "if I find a time at home I watch TV and not time remains for walking".

\section{Difficulty of observing a regular pattern}

"I prefer to consume medicine for weight loss and blood glucose reduction. It is easy. But not exercise. It is difficult to me. I can't help it".

\section{Inadequate physical readiness}

The participants pointed out not being used to exercise and the lack of physical preparedness as another obstacle for physical activity.

"Our parents were our models and they should 
have encouraged us to exercise in life and made us accustomed to exercise. My body aches when I walk a little; I am not used to it" (participant No. 21).

\section{Being ashamed}

"I am ashamed to go to swimming pool because I am obese. My sister goes there always and recommends me to go but I do not accept" (participant No. 14).

\section{Possibility of abuse}

"when the weather is good, I like to walk but the outside environment whether it is park or sidewalk where I want to walk is not safe. I do not like to go at all".

\section{Self-efficacy}

\section{Lack of ability to do regularly and continuously:}

The participant No. 27 mentioned her experiences in this regard as follows: "I do exercise but I cannot do it regularly. I exercise one week but not the subsequent week, especially when I am tired or I travel".

\section{The ability to restart:}

The participants pointed out that if they stop physical activity for a while, with the increase of blood glucose or lipid again, they can restart physical activity. In this regard, participant No. 4 said: "I will bring back my blood glucose to the normal level in a week because I want to go walking not stop it".

\section{Discussion}

The results of the present study indicate that the exercise behavior of women with prediabetes based on PEN-3 model is influenced by perceptual factors categories which consists of knowledge, attitude, beliefs (benefits, threat, perceived barriers and Self-efficacy) and values that act as facilitators or inhibitors of motivation for behavior change. The findings indicated that despite women's positive perceptions regarding physical activity, there are many negative perceptions that prevent women from doing physical activity. Women with prediabetes knew about the cause of their affliction with the disease but did not have knowledge about the appropriate time, duration, type and intensity of physical activity considering their condition. Lack of enough knowledge will result in the reduction of motivation and inability to properly plan for physical activity. This result is consistent with the results of the studies by Niknami (14), Hosseinzadeh (15) and Didarloo (16). The finding on attitude indicated that most of the participants viewed doing physical activity as enjoyable and were interested in doing physical activities...despite having high understanding and positive attitude regarding physical activity, they would not do this behavior regularly and continuously or if they did, it was for a short period of time. This study is consistent with the results of the study by Roberts and
Marvin (17) who showed that the individuals studied, despite having knowledge of physical activity, were not able to regularly do physical activity. The study of texts indicated that merely giving information to individuals is not effective and will not result in change in individuals' behaviors. Therefore, it is necessary to pay attention to values, behavior obstacles, motivations and objectives in individuals, in addition to knowledge (18). In the present study, women who had seen complications of high blood glucose (such as foot ulcers, blindness, foot amputation) in their diabetic family members, felt at risk of those complications and would do physical activity. But most of the women would not pay enough attention to physical activity and also believed that if their disease had been serious, their doctor would have prescribed medicine for them. In the studies by Sabzmakan and Morowatisharifabad, perceived threat in diabetic patients, especially those who had seen the complications resulted from high blood glucose in their family and relatives, was higher than patients with prediabetes $(18,19)$. It is recommended that health centers be participated in educational categories of the diabetics who have experienced diabetes complications so that they present their experiences or educational films be used for making disease complications tangible. Among the positive perceptual factors of most of the participants was the benefits resulted from physical activity that consisted of 4 subcategories of physical health and wellbeing, mental health, prevention of complications and the lack of need to consume medicine. In other studies, physical and mental health have been pointed out as factors affecting doing physical activity in women (14, 20, 21). According to the findings of the study, in the subcategories of physical health and well-being, the benefits of physical activity such as swimming and walking in this study are consistent with the results of obtained by Shamsi and Downs (22, 23). Other perceived benefits of controlling blood glucose, blood lipid and blood pressure and reduction or maintaining body weight pointed out included reduction of pain in the body that were perceived by the participants as positive perceptual factors. And this results are similar to the findings of the study by Ghazanfari et al. (14). Mental health and well-being was another subcategories of perceived benefits by women that was identified. The participants considered physical activity effective in reducing stress and anxiety, depression and emergence of feeling of joy and happiness and consequently, improvement of mental performance. This result is consistent with the results obtained by Salehi and Rashidi (24, 25). In our study, the women with prediabetes pointed out the lack of affliction with diabetes and prevention of its complications such as cardiac disease, blindness, kidney failure and foot ulcer and consequently the lack of need for consuming medicine to be among the long-term benefits of physical 
activity that lead to health and longevity; these results are similar with the results of the study by Ghazanfari et al. (14). Most of the participants pointed out physical and mental health improvement as a benefit of physical activity and exercise which is consistent with the results of the study by Downs (23). The participants had high perceived benefits that may be due to the education of the experts and physician at the center or maybe they knew the benefits of doing physical activity and exercise due to the education provided by the media. But, despite believing in having a regular exercise plan and understanding its benefits, especially walking, they felt many inhibiting barriers. Continuous training of physical activity benefits using new and diverse educational methods by the employees of the health centers working in the domain of education individuals with prediabetes is recommended. In our study, lack of exercise partner has been one of the barriers of physical activity among the participants. In the studies by Naderian and Nadri, lack of partner was one of the barriers of doing exercise $(26,27)$. Thus, encouraging peers and holding group exercise programs such as group walking programs by the implementers of exercise promotion programs seem to be necessary and should be on the top of exercise programs. Another barrier mentioned was limitation of time as most of the participants in the study were housewives and, due to having family responsibilities such as housework, taking care of children and nursing or other works outside the house, they had shortage of time. Laziness, boredom, tiredness and lack of motivation have been pointed out as a barrier for doing physical activity (18, $28,29)$ which is consistent with the results of the present study. Lack of physical readiness for doing physical activity or having a physical problem have also prevented women from doing physical activity, especially walking. This finding in the present study is consistent with the results obtained by Dansie (30), Wideman (31) and Hosseinzadeh (15). Being ashamed was another intra-individual barriers mentioned by women whose reason has been mostly pointed out to be obesity and being ashamed of one's body and consequently refraining from going to sports centers including swimming pools. Folta (32) and Korkiakangas (29) pointed out shame as a barrier to physical activity. Another reason for the lack of physical activity and exercise in women was mental problems and disorders, especially stress, anxiety, sadness and anger. This result is consistent with the results of the studies by Niknami (14) and Zarepoor (33). In the present study, the main problem of women in doing physical activity and especially walking was that they were not able to do it continuously and regularly and this refers to Schwarzer's maintenance self-efficacy. This means that despite the difficulty of the behavior and the existence of barriers, the individual is confident of her ability in maintaining that behavior.
Despite lack of maintenance self-efficacy, with the reincrease of blood glucose, most women were able to restart physical activity after its stopping due to barriers. This means the belief in restart of activity after a pause and resuming that behavior after a recurrence (34). Therefore, different studies indicated that the more confident individuals are about their efficacy and ability in doing self-care behaviors such as physical activity, the more they do the behavior in question which is consistent with the results of our study (35, 36).

Overall, the results of the qualitative section of this study indicated that most women with prediabetes have perceived factors such as perceived barriers and Self-efficacy in doing physical activity, considering barriers, to be more important as the other determinants as the cause of lack of physical activity and health center employees verified this. And, of course, other factors (knowledge, attitude, benefits, perceived threat) too play a significant role in the improvement of physical activity behavior; therefore, paying attention to these variables in designing educational programs is necessary.

\section{Conclusion}

The results of this study indicated that positive and negative perceptual factors as facilitators and inhibitors respectively can impact the individual's amount of physical activity. The identification of these perceptions and internal perceptions will help educators and other health experts in designing appropriate educational programs for intervention. Thus, those responsible for providing services to individuals with prediabetes, by considering impactful positive perceptual factors and resolving negative perceptions in doing physical activity, can facilitate physical activity in women with prediabetes, and, after the increase of motivation, exercise and physical activity, lead to the improvement of physical and mental health in women with prediabetes and prevent their affliction with type 2 diabetes. It should be noted that, in designing educational programs for the target population, it is important to pay attention cultural factors impacting behavior.

\section{Acknowledgement}

The authors would like to thank the management and employees of county health center and the health centers of Dezful, without whose cooperation this study would not have been possible.

\section{References}

1. Fazelian S, Olia AS, Mirfatahi M, Hoseini M, Yganeh HS, Heshmati J, Namazi N. Effect Of LArginine Supplementation On Antioxidant Enzyme Activity, Total Antioxidant Capacity And Body Composition In Patients With Pre-Diabetes. Arak 
Medical University Journal. 2013 Jan 1;16(78):2535.

2. American Diabetes Association. Standards Of Medical Care In Diabetes-2010. Diabetes Care. 2010 Jan;33(Suppl 1):S11.

3. Shaw JE, Sicree RA, Zimmet PZ. Global Estimates Of The Prevalence Of Diabetes For 2010 And 2030. Diabetes Research And Clinical Practice. 2010 Jan $1 ; 87(1): 4-14$.

4. Eatemady $\mathrm{Ba}$, Kargarfard $\mathrm{M}$, Mojtahedi $\mathrm{H}$, Rouzbehani R, Dastbarhagh H. Comparison Of The Effects Of 8-Weeks Aerobic Training And Resistance Training On Lipid Profile In Patients With Diabetes Type 2.

5. Mazloomy S, Mirzaei A, Afkhami Ardakani M, Baghiani Moghadam M, Fallahzadeh H. The Role Of Health Beliefs In Preventive Behaviors Of Individuals At High-Risk Of Type2 Diabetes Mellitus. SSU Journals. 2010 Apr 15;18(1):24-31.

6. Brown G, Schebella Mf, Weber D. Using Participatory Gis To Measure Physical Activity And Urban Park Benefits. Landscape And Urban Planning. 2014 Jan 1;121:34-44.

7. Strobl R, Müller $M$, Thorand B, Linkohr B, Autenrieth CS, Peters A, Grill E. Men Benefit More From Midlife Leisure-Time Physical Activity Than Women Regarding The Development Of Late-Life Disability-Results Of The KORA-Age Study. Preventive Medicine. 2014 May 1;62:8-13.

8. Mirhosseini $M$, Esfarjani $F$, Marandi $M$, Khalilzadeh SH, Mirhosseini H. The Effect Of Yoga Exercise On Parameters Of Type II Diabetes. Journal Of Shahid Sadoughi University Of Medical Sciences. 2014 Jan 1;22(1):880-91.

9. Peyman N, Ezzati Rastgar Kh, Tehrani $\mathrm{H}$. Effectiveness Of Education By Pen -3 Cultural Model On Improve Feeding Behaviors In Adolescent Girls With Obesity And Over Weight In Razan City.2013;18(5):254-260.

10. Airhihenbuwa CO. Culture Matters Inglobal Health. The Eur Health Psychol J 2010;12(4): 52-55.

11. Shahbazi H, Ghofranipour F , Amiri P, Rajab A . Perceptions, Enablers And Nurturers Related To Self-Care Behaviors In Adolescent With Type 1 Diabetes.IJEM. 2018, 19(6): 435-443.

12. Graneheim UH, Lundman B. Qualitative Content Analysis In Nursing Research: Concepts, Procedures And Measures To Achieve Trustworthiness. Nurse Education Today. 2004 Feb 1;24(2):105-12.

13. Vicent. N. A. (2014). Ensuring The Quality Of The Findings Of Qualitative Research: Looking At Trustworthiness Criteria. Journal Of Emerging Trends In Educational Research And Policy Studies. 5(2):272-281.

14. Ghazanfari Z, Niknami S, Ghofranipour F, Larijani B. Regular Physical Activity From Perspective Of
Females With Diabetes: A Qualitative Study. The Horizon Of Medical Sciences. 2009 Apr 15;15(1):514.

15. Hossinzadeh K,Niknami Sh. Determinants Of Family's Self-Efficacy For Physical Activity; A Qualitative Study. Journal Of Health. 2018, 7(3): 288-301.

16. Didarloo AR, Shojaie Zadeh D, Eftekhar H, Niknami S, Haji Zadeh I, Ali Zadeh M, Et Al. Physical Activity Among Women With Type 2 Diabetes: Prediction By The Extended Theory Of Reasoned Action. Payesh 2012, 11(2): 0-187.

17. Roberts K, Marvin K. Knowledge And Attitudes Towards Healthy Eating And Physical Activity: What The Data Tell Us. National Obesity Observatory. 2011;3:1-39.

18. Sabzmakan L, Asghari Jafarabadi M, Nikpajouh A, Bakhtari F. Determinants Of Physical Activity Among Patients With Cardiovascular Metabolic Risk Factors Based On The Educational Factors Of PRECEDE Model: A Mixed Method Study. Iranian Journal Of Health Education And Health Promotion. 2016 Jun 15;4(1):5-19.

19. Morowatisharifabad MA, Mohammadi E. Patients, Experiences With Cardiovascular Disease Risk Factors And Healthcare Providers Of Determinants Of The Nutritional Behavior: A Qualitative Directed Content Analysis. Iranian Journal Of Endocrinology And Metabolism. 2013 Oct 15;15(3):292-302.

20. Jurkowski JM, Mosquera M, Ramos B. Selected Cultural Factors Associated With Physical Activity Among Latino Women. Women's Health Issues. 2010 May 1;20(3):219-26.

21. Hazavehei SM, Pirzadeh A, Entezari MH, Hasanzadeh A. The Effect Of Educational Program Based On BASNEF Model On The Nutritional Behavior Of Students. Zahedan Journal Of Research In Medical Sciences. 2011 Mar 1;13(1):23-9.

22. Shamsi M, Sharifirad G, Kachoyee A, Hassanzadeh A. The Effect Of Educational Program Walking Based On Health Belief Model On Control Sugar In Woman By Type 2 Diabetics. Iranian Journal of Endocrinology And Metabolism. 2009;11(5):490597.

23. Downs DS, Hausenblas HA. Elicitation Studies And The Theory Of Planned Behavior: A Systematic Review Of Exercise Beliefs. Psychology Of Sport And Exercise. 2005 Jan 1;6(1):1-31.

24. Salehi L, Taghdisi MH, Ghasemi H, Shokervash B. To Identify The Facilitator And Barrier Factors Of Physical Activity Among Elderly People In Tehran. Iranian Journal Of Epidemiology. 2010 Sep 15;6 (2):7-15.

25. Rashidi Z, Rashidi A, Rouzbahani R, Rezaei F. Effects Of Group Exercise On Women's Depressive Symptoms. Journal Of Isfahan Medical School. 2013 Jan 8;30(212). 
26. Naderian M, Zolaktaf V. Moshkelgoshaelham, Barriers To Female Sport Participation And Their Relationship With Motivation. Journal Of Movement Science And Sport. 2009(13):145-54.

27. Nadri A, Safania A, Amritash A. Determinant Of The Implementation Of Physical Activities In Elderly In Tehran. Joge. 2016; 1 (2):66-79

28. Motameni A, Hemmati A. Identifying And Prioritizing The Barriers For Women's Sports Activities. Journal Of Sport Management Review. 2014 Sep 15;6(24):111-30.

29. Korkiakangas EE, Alahuhta MA, Laitinen JH. Barriers To Regular Exercise Among Adults At High Risk Or Diagnosed With Type 2 Diabetes: A Systematic Review. Health Promotion International. 2009 Sep 30;24(4):416-27.

30. Dansie EJ, Turk DC, Martin KR, Van Domelen DR, Patel KV. Association Of Chronic Widespread Pain With Objectively Measured Physical Activity In Adults: Findings From The National Health And Nutrition Examination Survey. The Journal Of Pain. 2014 May 1;15(5):507-15.

31. Wideman TH, Finan PH, Edwards RR, Quartana PJ, Buenaver LF, Haythornthwaite JA, Smith MT. Increased Sensitivity To Physical Activity Among Individuals With Knee Osteoarthritis: Relation To Pain Outcomes, Psychological Factors, And
Responses To Quantitative Sensory Testing. PAIN®. 2014 Apr 1;155(4):703-11.

32. Folta SC, Goldberg JP, Seguin R, Reed PN, Nelson ME, Lichtenstein AH. Peer Reviewed: Factors Related To Cardiovascular Disease Risk Reduction In Midlife And Older Women: A Qualitative Study. Preventing Chronic Disease. 2008 Jan;5(1).

33. Zarepoor F, Kamali M, Alagheband M, Gheisari M, Sarlak S. Evaluation Of Depression And Its Relationship To Exercise In Women Over 20 Years. SSU_Journals. 2012;20(1):64-72.

34. Schwarzer R. Modeling Health Behavior Change: How To Predict And Modify The Adoption And Maintenance Of Health Behaviors. Applied Psychology. 2008 Jan;57(1):1-29.

35. Morowatisharifabad M, Tonekaboni NR. Perceived self-efficacy in self-care behaviors among diabetic patients referring to Yazd Diabetes Research Center. Journal of Birjand University of Medical Sciences. 2009;15(4):91-9.

36. Shakibazadeh E, Rashidian A, Larijani B, Shojaeezadeh D,Forouzanfar M, Karimi Shahanjarini A. Perceived Barriers And SelfEfficacy: Impact On Self-Care Behaviors In Adults With Type 2 Diabetes. Hayat Journal Of Faculty Of Nursing And Midwifery. 2010;15(4):69-78. 